\title{
Development of three-dimensional lung multicellular spheroids in air- and liquid-interface culture for the evaluation of anticancer therapeutics
}

\author{
SAMANTHA A. MEENACH ${ }^{1,2,4^{*}}$, ALEXANDRA N. TSORAS ${ }^{2 *}$, RONALD C. McGARRY $^{3}$, \\ HEIDI M. MANSOUR ${ }^{1,5}$, J. ZACH HILT ${ }^{2}$ and KIMBERLY W. ANDERSON ${ }^{2}$
}

\begin{abstract}
${ }^{1}$ Department of Pharmaceutical Sciences - Drug Development Division, University of Kentucky, Lexington, KY 40536; ${ }^{2}$ Department of Chemical and Materials Engineering, University of Kentucky, College of Engineering, Lexington, KY 40506; ${ }^{3}$ Department of Radiation Medicine, University of Kentucky, Lexington, KY 40536, USA
\end{abstract}

Received December 9, 2015; Accepted January 21, 2016

DOI: 10.3892/ijo.2016.3376

\begin{abstract}
Three-dimensional (3D) lung multicellular spheroids (MCS) in liquid-covered culture (LCC) and air-interface culture (AIC) conditions have both been developed for the evaluation of aerosol anticancer therapeutics in solution and aerosols, respectively. The MCS were formed by seeding lung cancer cells on top of collagen where they formed spheroids due to the prevalence of cell-to-cell interactions. LCC MCS were exposed to paclitaxel (PTX) in media whereas AIC MCS were exposed to dry powder PEGylated phospholipid aerosol microparticles containing paclitaxel. The difference in viability for 2D versus 3D culture for both LCC and AIC was evaluated along with the effects of the particles on lung epithelium via transepithelial electrical resistance (TEER)
\end{abstract}

Correspondence to: Dr Samantha A. Meenach, ${ }^{4}$ Present address: Department of Chemical Engineering, University of Rhode Island, 205 Crawford Hall, 16 Greenhouse Road, Kingston, RI 02881, USA E-mail: smeenach@uri.edu

Present address: ${ }^{5}$ Department of Pharmacy Practice and Science, University of Arizona, Tuscon, AZ 85721, USA

\section{${ }^{*}$ Contributed equally}

Abbreviations: 3D, three-dimensional; MCS, multicellular spheroids; LCC, liquid covered culture; AIC, air-interface culture; PTX, paclitaxel; TEER, transepithelial resistance; 2D, two-dimensional; ECM, extracellular matrix; MPs, microparticles; DPPC; dipalmitoylphosphatidylcholine; DPPE-PEG3k, dipalmitoylphosphatidylethanolamine methoxy(polyethylene glycol) 3000 EE, encapsulation efficiency; PEG, poly(ethylene glycol); FBS, fetal bovine serum; DMEM, Dulbecco's Modified Eagle Medium; NBD-PC, nitrobenzooxadiazole phosphatidylcholine, $\mathrm{IC}_{50}$, halfmaximal inhibitory concentration

Key words: multicellular spheroids, air interface culture, paclitaxel, three-dimensional cell culture, lung cancer measurements. For LCC and AIC conditions, the 3D spheroids were more resistant to treatment with higher $\mathrm{IC}_{50}$ values for A549 and H358 cell lines. TEER results initially indicated a decrease in resistance upon drug or particle exposure, however, these values increased over the course of several days indicating the ability of the cells to recover. Overall, these studies offer a comprehensive in vitro evaluation of aerosol particles used in the treatment of lung cancer while introducing a new method for culturing lung cancer MCS in both LCC and AIC conditions.

\section{Introduction}

Patients in the United States die from lung cancer more than any other individual cancer diagnosis (1). While surgical resection is the standard of care for early stage lung cancer, only $25 \%$ of patients have resectable disease at the time of diagnosis (2). As a result, current practice guidelines recommend these patients be treated with a combination of chemotherapy and radiation (3). In vitro cell culture models are a major factor in analyzing the effectiveness of cancer therapeutics. In lung cancer specifically, there are many characteristics of a tumor that need to be altered in an in vitro cell culture model in order for it to be as physiologically representative as possible. In order to do this, many aspects of the cell culture methods have to be improved. Specifically, a model that is three-dimensional (3D), possesses a surrounding environment that is similar to an in vivo tumor, yields proliferating cells, and is set up so that cells can be exposed to air (as cancer cells are in the lung) needs to be established.

To start, the use of 3D multicellular spheroids (MCS) allows for a more tumor-like environment to evaluate chemotherapeutic drugs. MCS are small, tightly bound cellular aggregates that tend to form when cells are maintained under non-adherent conditions. These aggregates can range in size from $20 \mu \mathrm{m}$ up to $1 \mathrm{~mm}$ in diameter depending on the cell type and growth conditions (4). Testing anticancer drugs in 3D culture models will better simulate the tumor microenvironment and signaling pathways that are functional in tissues and organs and can potentially provide a better correlation between 
in vitro screening and in vivo animal models (5). Tumor spheroids are also considered an improved in vitro model to mimic biological properties of micrometastases and vessel distal regions of tumors because they retain the architecture and many morphological and physiological characteristics of their tumor counterparts (6).

MCS can mimic avascular in vivo tumors in that they have diffusion limitations for many molecules, including oxygen, and this inefficient mass transport leads to metabolic waste accumulation inside the MCS so that they display a layer-like structure comprised of a necrotic core surrounded by a viable rim of cells $(7,8)$. It is the center of a tumor that exhibits a hostile microenvironment. This environment harbors the most aggressive tumor cells, which will regenerate if they are not eliminated. MCS have been effectively used to study many types of therapeutics including nanoparticles, chemotherapeutics, and radiation where the MCS show significant differences in response in comparison to two-dimensional (2D) cell monolayers $(9,10)$. Most chemotherapeutic drugs affect actively proliferative tumor cells by either crosslinking DNA or interfering with the formation of the mitotic spindle. It is expected that these types of drugs would have a lesser effect on 3D MCS, which have a large fraction of quiescent cells. Also, the reduced diffusion of drugs through multiple cell layers and increased expression of drug transporters can result in drug resistance in MCS (11).

There are many methods for creating 3D MCS, the most common of these include liquid overlay, embedding in extracellular matrix (ECM) components, hanging drop, micromolding, spinner flask, rotary culture, and centrifugation methods $(7,12)$. Several of these methods have been utilized in the development of 3D spheroid models of lung cancer for the evaluation of solution-based anticancer therapeutics. For example, both A549 lung adenocarcinoma cells and primary lung cancer cells have been grown via the liquid overlay method on agarose $(13,14)$ or poly(2-hydroxyethyl methacrylate) (pHEMA) (6). Vertrees et al created spheroids of a transformed cell line (BZR-T33) over several weeks in a rotating wall vessel (15). A high throughput method of spheroid creation was developed where H1650 lung cancer cells were formed in mini-ports on a microchip (16). A549 spheroids were embedded in Matrigel ${ }^{\mathrm{TM}}$ which contains ECM components and both A549 and H358 cells were embedded in collagen for the formation of spheroids $(5,17,18)$. Despite these initial studies, they all pose disadvantages in the study of aerosol therapeutics including drug diffusion limitations through ECM-based matrices for the embedded method, challenges in implementation for the microchip method, the need for specialized equipment for rotating wall vessel method, and lack of air-interface conditions for the liquid overlay method.

The purpose of this current study was develop an in vitro lung tumor spheroid model that could mimic in vivo tumor shape, behavior, and environment more closely and effectively and to observe the effects of both solution-based and aerosolbased therapeutics on this model. In liquid overlay culture, culture plates are usually coated with a non-adhesive, partially hydrophilic material to create a surface on which the cells, once seeded, are more inclined to attach to each other than to the culture surface, thereby initiating the formation of spheroids on the surface of the collagen. The spheroids are grown in solution using a liquid-covered culture (LCC) method which allows for the evaluation of drug in solution. Subsequently, this system can be modified where the spheroids are formed on collagen in Transwells ${ }^{\circledR}$ where the media is then removed to allow the spheroids to be grown in air-interface culture (AIC) conditions. This will allow for the evaluation of aerosol-based therapeutics.

One of the current limitations in the evaluation of aerosolbased therapeutics for lung cancer is the lack of cell culture models for the evaluation of their efficacy. The described work allows for the evaluation of effectiveness of such therapeutics on 2D cells and 3D spheroids grown in AIC conditions as well as the evaluation of the safety of these systems using transepithelial resistance (TEER) analysis. When grown using AIC, primary cell layers resemble the native epithelium to a greater extent than cells grown using LCC (19). Furthermore, the growth of spheroids in AIC conditions is more physiologically representative than LCC and allows the direct testing of aerosol therapeutics on the cells rather than having to dissolve/ disperse them in solution. TEER is a measurement of the electrical resistance across a cell monolayer and this measurement can be used to analyze the permeability of the cells in a monolayer. TEER reduction has been used as an indication of adverse effects of model toxicants and inhaled delivery vehicles and corresponds well with standard toxicological tests $(20,21)$. Ensuring that there is no significant change in the permeability of lung cancer cells is important in showing the safety of the aerosol therapeutic. Calu-3 lung cells have already been established for use in TEER studies for both LCC and AIC conditions $(19,22,23)$.

Paclitaxel (PTX) was selected as the model therapeutic as it is widely used in the treatment of non-small cell lung cancer via intravenous delivery $(24,25)$ and is being investigated in aerosolized formulations for the treatment of lung cancer (26-28). Our group has developed dry powder PEGylated phospholipid microparticles containing PTX that show optimized aerodynamic diameters, release, and aerosol dispersion properties $(29,30)$. These were selected to act as the model for an aerosol treatment for lung cancer for the validation of the AIC 3D MCS model. Overall, this study outlined the pertinent physicochemical characteristics of the dry powder aerosol microparticles, which were used and the in vitro characterization of both the dry powders and PTX in solution. This particular characterization included evaluating the activity of the PTX encapsulated in the particles, uptake of the particles into A549 cells, development of the lung MCS in LCC and AIC conditions, efficacy of the solution-based and aerosol particle treatments, and safety of the aerosol particles using TEER. These studies may potentially act as a model for the more comprehensive evaluation into the efficacy and safety of aerosol particles in vitro prior to more time-consuming and expensive in vivo experiments.

\section{Materials and methods}

Materials. Fetal bovine serum (FBS), penicillin-streptomycin solution and trypsin/EDTA were obtained from American Type Culture Collection (ATCC, Manassas, VA). Calcein AM, ethidium homodimer-1, Dulbecco's modified Eagle's medium (DMEM), sodium pyruvate, Fungizone ${ }^{\circledR}$, Lysotracker ${ }^{\circledR}$ Red, 
Hoescht 3342, and L-glutamine were obtained from Invitrogen (Grand Island, NY, USA). DMSO and resazurin sodium salt were obtained from Sigma-Aldrich (St. Louis, MO, USA) and collagen I (rat tail) was from BD Biosciences (San Jose, CA, USA). Synthetic dipalmitoylphosphatidylcholine (DPPC, molecular weight (MW): $734.039 \mathrm{~g} / \mathrm{mol}$; >99\% purity) and dipalmitoylphosphatidylethanolamine-methoxy(polyethylene glycol) (DPPE-PEG3k, MW $3716.304 \mathrm{~g} / \mathrm{mol}$ which corresponds to 3000 molecular weight poly(ethylene glycol) length per compound; $>99 \%$ purity) were obtained from Avanti Polar Lipids (Alabaster, AL, USA). Paclitaxel was obtained from LC Laboratories (Woburn, MA, USA; 99.5\% purity). All materials were used as received.

Cell lines and culturing conditions. H358 (bronchioalveolar carcinoma) and A549 (lung adenocarcinoma) cells were obtained from ATCC and were cultured in medium comprised of DMEM, 10\% FBS, 4 mM L-glutamine, 1 mM sodium pyruvate, $0.25 \mu \mathrm{g} / \mathrm{ml}$ Fungizone, $100 \mathrm{IU}$ penicillin, and $100 \mu \mathrm{g} / \mathrm{ml}$ streptomycin. The cells were grown at $37^{\circ} \mathrm{C}$ and $5 \% \mathrm{CO}_{2}$ in a humidified atmosphere.

Dry powder particle synthesis and PTX loading. Dry aerosol powders were synthesized via spray drying as described previously by our group $(29,30)$. PEGylated phospholipid particles were made by mixing DPPC and DPPE-PEG3k (95:5 molar ratio) with $1,5,25$, and $50 \mathrm{~mol} \%$ paclitaxel relative to the total phospholipid amount in methanol (hereby abbreviated as $1 \%$ PTX MPs, 5\% PTX MPs, 25\% PTX MPs, and 50\% PTX MPs, respectively, where MPs refers to microparticles). The solutions were then spray dried to produce particles approximately $1 \mu \mathrm{m}$ in diameter (30). UV-Vis was used to determine the amount of paclitaxel loaded into the formulated particle systems. The particles were dissolved in known quantities of methanol prior to analysis. The absorbance intensity was measured at $227 \mathrm{~nm}$ using a Synergy Mx BioTek microplate reader. The paclitaxel encapsulation efficiency (EE) and loading was calculated as follows:

$$
\begin{gathered}
\mathrm{EE}=\frac{\text { Actual mass of PTX }}{\text { Initial mass of PTX }} \times 100 \% \\
\text { Drug loading }=\frac{\text { Actual mass of PTX }}{\text { Mass of particles }}
\end{gathered}
$$

Particle internalization/Uptake study. A549 cells were exposed to $25 \%$ PTX MPs loaded with 1 mol\% nitrobenzoxadiazole phosphatidylcholine (NBD-PC) to allow for fluorescent imaging of the particles. Cells/well $(60,000)$ were seeded into an 8-well chamber slide and were left to attach for $24 \mathrm{~h}$. They were then exposed to $1 \mathrm{mg} / \mathrm{ml}$ of particles in media for 6 and $24 \mathrm{~h}$. After exposure, the cells were washed with a $200 \mathrm{mM}$ glycine solution to remove any non-internalized particles and were then stained with $7.5 \mathrm{nM}$ Lysotracker Red and $10 \mu \mathrm{M}$ Hoescht 33342 prior to live imaging. Imaging was completed using a Nikon Eclipse 80i microscope.

A549 viability/Particle activity study. The activity of the paclitaxel present in the particles was evaluated by exposing A549 cells to various concentrations of PTX-loaded micro- particles and free (raw) paclitaxel. A549 cells were seeded at 3,000 cells/well in 96-well plates for $48 \mathrm{~h}$ followed by exposure to PTX-loaded particles or PTX diluted in DMSO from 0.0001 to $1 \mu \mathrm{M}$ in media. The PTX was initially dissolved in DMSO at its highest solubility and then diluted with media for further PTX concentrations. The amount of DMSO was kept constant at $0.1 \% \mathrm{v} / \mathrm{v}$ for all PTX concentrations (also the control), including for PTX-loaded microparticle samples. A control of particles without PTX was also evaluated using the same amount of particles as the particle system with the lowest concentration of PTX. At $72 \mathrm{~h}$ after exposure, the cells were exposed to $2 \mathrm{mM}$ of resazurin for $3 \mathrm{~h}$. The fluorescence intensity of the resulting resorufin was measured using a Synergy Mx BioTek microplate reader at 579/584 nm (excitation/emission) wavelengths. The relative viability was then evaluated as the fluorescence intensity of the sample divided by the fluorescence intensity of control cells (no treatment).

Two-dimensional cell culture evaluation of paclitaxel and paclitaxel-loaded dry powder particles. Cells were grown in both air-interface culture (AIC) and liquid-covered culture (LCC) conditions to determine the half-maximal inhibitory concentration $\left(\mathrm{IC}_{50}\right)$ for $2 \mathrm{D}$ culture conditions. For the $\mathrm{LCC}$ condition, $\mathrm{H} 358$ and A549 cells were seeded in 96-well plates at 7,500 and 3,000 cells/well, respectively. After $48 \mathrm{~h}$, the cells were exposed to PTX $(0.0001$ to $1 \mu \mathrm{M})$ where all PTX solutions contained $0.1 \%(\mathrm{v} / \mathrm{v}) \mathrm{DMSO}$ in medium to aid in PTX solubility. For AIC conditions, H358 and A549 cells were seeded in Transwells $(0.4 \mu \mathrm{m}$ polyester membrane, $12 \mathrm{~mm}$, 12 -well plate) at 22,000 and 14,000 cells/well, respectively, with $0.5 \mathrm{ml}$ media on the apical side and $1.5 \mathrm{ml}$ of media on the basolateral side of the Transwell. At $24 \mathrm{~h}$ after seeding, media was removed from the apical side and the basolateral side was reduced to $0.5 \mathrm{ml}$ to induce AIC conditions. After a further $24 \mathrm{~h}$, the cells were exposed to $1 \mathrm{mg}$ of each particle type (blank, 1, 5, and 25\% PTX MPs) using a $1 \mathrm{ml}$ syringe and $21 \mathrm{G}$ needle to aerosolize the particles onto the cells. At $72 \mathrm{~h}$ after exposure to PTX, the viability of the cells was determined via a resazurin (viability) assay as described above $(0.5 \mathrm{ml}$ of media was added to the AIC cells prior to the analysis). $\mathrm{IC}_{50}$ values were determined using SigmaPlot 12.0 software.

Three-dimensional multicellular spheroid (MCS) formation. MCS were formed on type I rat tail collagen which was used because of its non-adhesive nature to more prominently induce cell-to-cell interactions. LCC and AIC conditions were induced by seeding cells onto collagen in 24-well plates and Transwell, respectively, and the visualization of this process can be seen in Fig. 1. Collagen solution was mixed according to the manufacturer's instructions. A $2.1 \mathrm{mg} / \mathrm{ml}$ collagen solution was pipetted into the plates and allowed to solidify at $37^{\circ} \mathrm{C}$ in an incubator for $30 \mathrm{~min}$. H358 and A549 cells were seeded at 10,000 cells/well and 7,500 cells/well, respectively $(0.5 \mathrm{ml}$ media and cells on the apical and $1.5 \mathrm{ml}$ of media on the basolateral side of the Transwells for AIC). For AIC conditions, the media was removed from the apical side after $24 \mathrm{~h}$. The size and morphology of the spheroids was determined via bright field imaging. During their growth and formation, the MCS were imaged daily and their diameter was analyzed using 


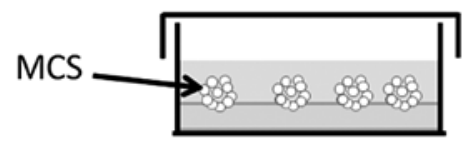

Liquid Overlay/ Liquid Covered Culture

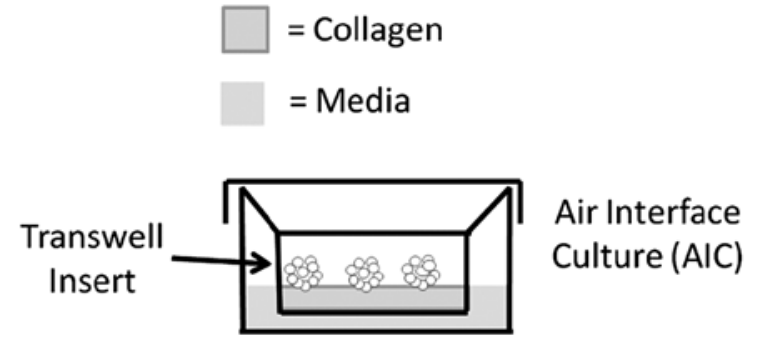

Figure 1. Schematic depicting liquid overlay culture (LCC) condition versus AIC conditions in the culturing of lung cancer multicellular spheroids (MCS).

NIS-Elements software. Both to PTX exposure as well as at the end of PTX exposure, the spheroids were stained using calcein AM and ethidium homodimer-1 and imaged to show the presence in live and dead cells, respectively.

Three-dimensional MCS evaluation of paclitaxel and paclitaxel-loaded dry powder particles. The cells were grown until spheroid formation was evident (4 days for H358 and 9 days for A549 cells). The evaluation of the effect of PTX on MCS was determined by exposing the cells to PTX utilizing the LCC condition and AIC condition where the drug was applied to the air interface of the cells via phospholipid dry powder aerosol containing PTX. For the LCC condition, the MCS were exposed to 0.0001 to $1 \mu \mathrm{M}$ PTX and for AIC condition, the MCS were exposed to blank, 1, 5 and 25\% PTX MPs as described above. After $72 \mathrm{~h}$, viability was determined using the resazurin assay. $\mathrm{IC}_{50}$ values were determined using SigmaPlot 12.0 software.

Transepithelial electrical resistance (TEER) analysis on lung cell monolayers. TEER evalution was completed using an EVOM2 epithelial voltammeter and $12 \mathrm{~mm}$ Endohm culture cup from World Precision Instruments (Sarasota, FL, USA). Calu-3 cells were seeded at 250,000 cells/well in Transwells. To induce AIC conditions, the media was removed from the cell monolayer after $24 \mathrm{~h}$ and was replaced and removed for TEER measurement only. TEER values were measured every other day for both AIC and LCC conditions. Upon reaching resistance equilibrium (after 5 days), the monolayer was exposed to phospholipid dry powder particles with or without PTX (AIC condition) as well as PTX in media (LCC condition). The resistance of the monolayer was again measured 2, 4, 24, 48, 72, 96 and $120 \mathrm{~h}$ after PTX or particle exposure. The reported resistance values are the actual resistance less the resistance due to a blank Transwell.

\section{Results and Discussion}

Dry powder PEGylated phospholipid microparticles (MPs) were used as a model system to demonstrate the validity of a 3D air-interface culture (AIC) multicellular spheroid model in the evaluation of aerosol lung therapeutics. The particles
Table I. PEGylated phospholipid microparticle systems containing paclitaxel, actual PTX encapsulation efficiency (EE), actual loading of PTX and PTX $\mathrm{IC}_{50}$ values corresponding to dose-response curve.

\begin{tabular}{lccc}
\hline System & $\begin{array}{c}\text { Actual } \\
\text { PTX EE } \\
(\text { wt } \%)\end{array}$ & $\begin{array}{c}\text { PTX Loading } \\
(\mathrm{mg} \text { PTX } / \mathrm{mg} \\
\text { particles })\end{array}$ & $\begin{array}{c}\mathrm{PTX} \mathrm{IC}_{50} \\
(\mu \mathrm{M})\end{array}$ \\
\hline Raw PTX & NA & NA & 0.0346 \\
1\% PTX MPs & $99.1 \pm 2.2$ & $0.010 \pm 0.001$ & 0.0053 \\
5\% PTX MPs & $96.6 \pm 1.2$ & $0.059 \pm 0.007$ & 0.0047 \\
25\% PTX MPs & $95.9 \pm 3.1$ & $0.268 \pm 0.009$ & 0.0030 \\
$50 \%$ PTX MPs & $98.2 \pm 2.1$ & $0.512 \pm 0.008$ & 0.0028 \\
\hline
\end{tabular}

were loaded with paclitaxel (PTX) at 1, 5, 25, and $50 \mathrm{~mol} \%$. Our previous work shows these particles to be approximately $1 \mu \mathrm{m}$ in diameter (30). PTX encapsulation efficiencies (EE) were high for all particle systems (at least 96.6 weight \%) and the actual EE values are listed along with the actual PTX loadings (mg PTX/mg particles) in Table I. This is ideal for aerosol drug delivery systems especially as it allows for the maximum amount of drug loading in the particle, allowing for minimal excess powder delivery while still maintaining optimal treatment properties.

The effect of the particles on lung cells was initially evaluated via both uptake and liquid-covered culture (LCC) viability studies. A549 cells were exposed to $1 \mathrm{mg} / \mathrm{ml}$ of $50 \%$ PTX MPs (the highest PTX loading) containing fluorescent NBD in media for 6 and 24 h. Fig. 2 includes representative combined fluorescent micrographs of cells exposed to particles and the subsequent controls. At $6 \mathrm{~h}$, there was some uptake of particles evident (green) with a significant amount of lysosome staining (red) where the nuclei were stained blue. The morphology and staining was similar for the control cells at $6 \mathrm{~h}$ in comparison to the cells exposed to particles. After the $24 \mathrm{~h}$ particle exposure, there was also particle uptake evident, however, there were much fewer cells attached to the slides in comparison to the control. This is likely due to the significant amount of cell death that would have occurred for this exposure time and PTX concentration. Overall, these results demonstrate the capability of the particles to internalize within lung epithelial cells, potentially enhancing the delivery of paclitaxel.

The activity of PTX in the particles after spray drying was evaluated by dispersing the particles in media and exposing A549 cells to various concentrations of PTX for $72 \mathrm{~h}$ to produce a dose-response curve. The viability for blank particles (without PTX) was $99 \pm 2 \%$ which was not significantly different from the control ( $\mathrm{p}>0.9$ ). While the resulting $\mathrm{IC}_{50}$ value of raw PTX (no spray drying) was $0.0346 \mu \mathrm{M}$, the $\mathrm{IC}_{50}$ values for the particles ranged from 0.0028 to $0.0053 \mu \mathrm{M}$ for the particle systems as seen in Table I. This 10-fold decrease in $\mathrm{IC}_{50}$ values could be due to the uptake of the particles into A549 cells and subsequent PTX release or as a result of paclitaxel binding with the serum present in the media, decreasing the effective dose of raw paclitaxel in media. In 

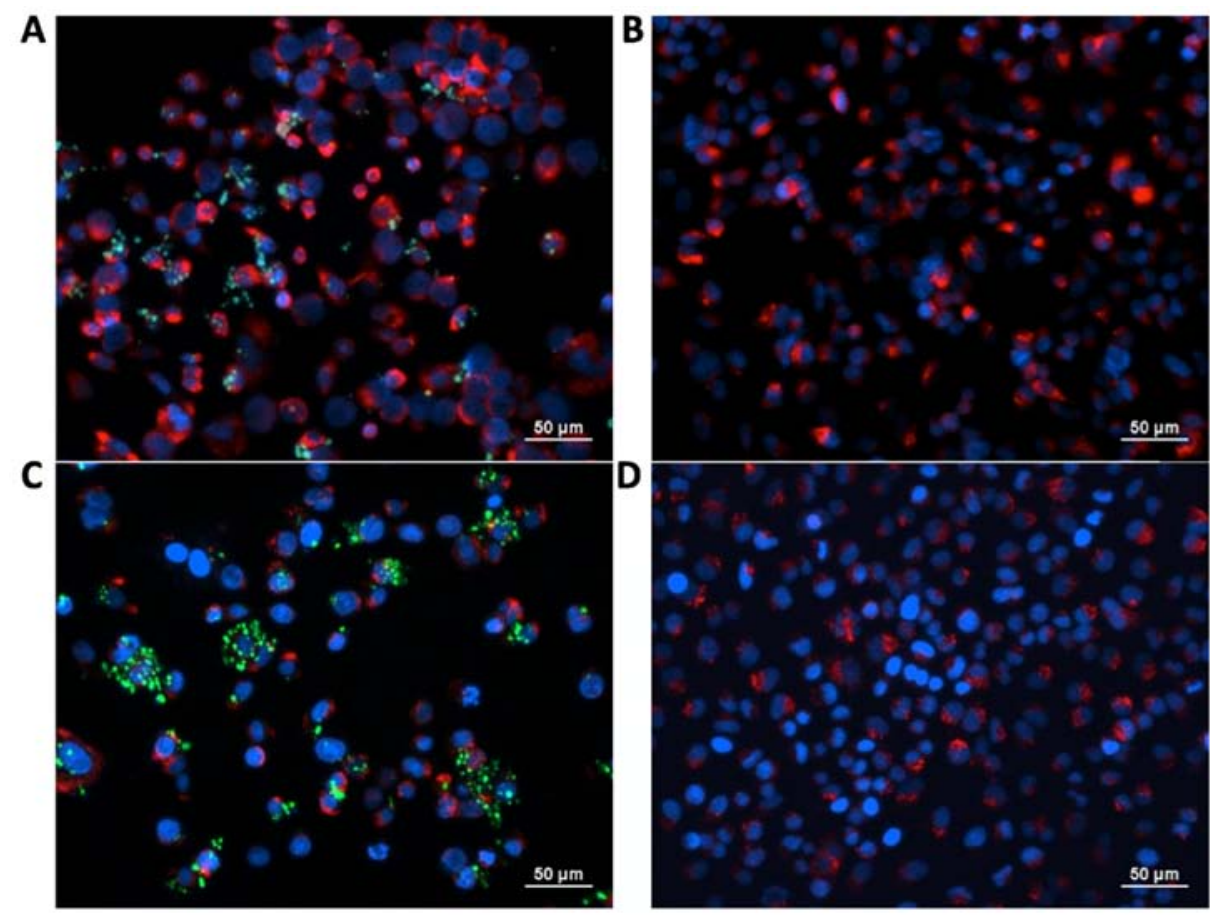

Figure 2. Representative fluorescent micrographs of A549 cells used in PEGylated phospholipid microparticle uptake studies where (A and B) are after $6 \mathrm{~h}$ of exposure, (C and D) are after $24 \mathrm{~h}$ of exposure. Cells in (A and C) were exposed to $1 \mathrm{mg} / \mathrm{ml}$ of $25 \%$ PTX MPs whereas (B and D) are control cells. Blue, red, and green fluorescent staining represent the cell nuclei, cell cytoskeleton, and microparticles, respectively. Scale bar, $50 \mu \mathrm{m}$.
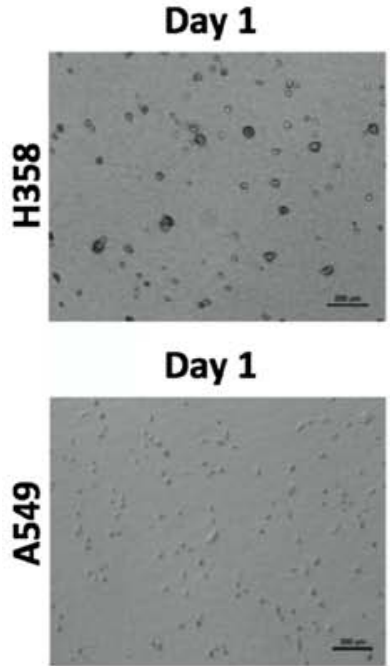

Day 2

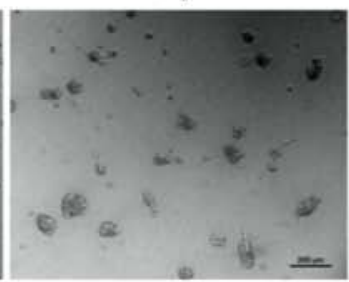

Day 3
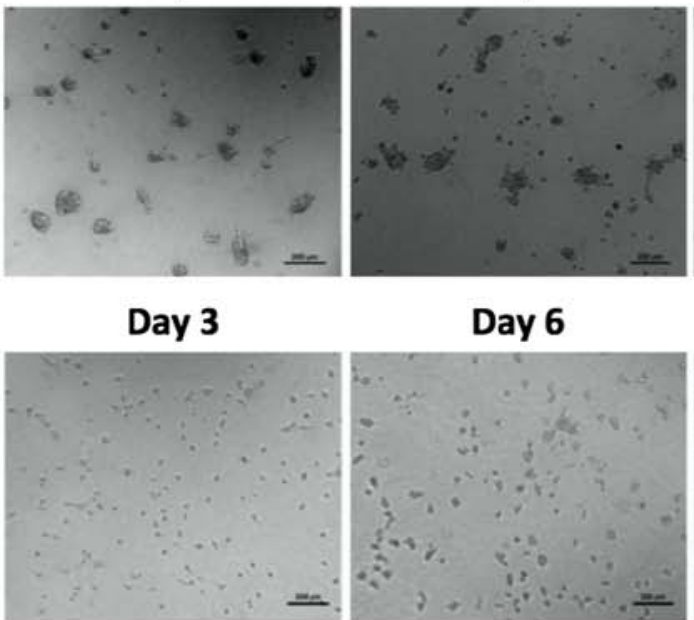

Day 3

Day 6

Day 4

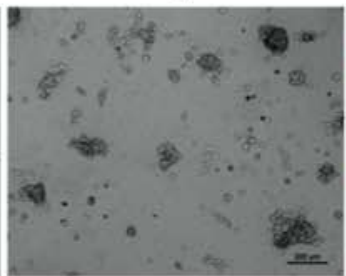

Day 9
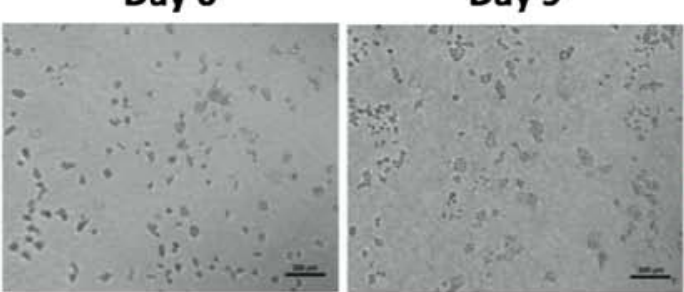

Day 6

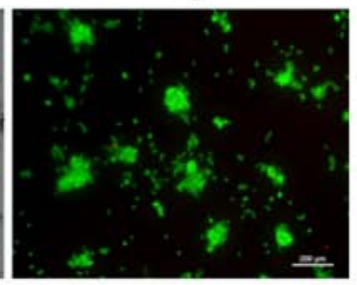

Day 12

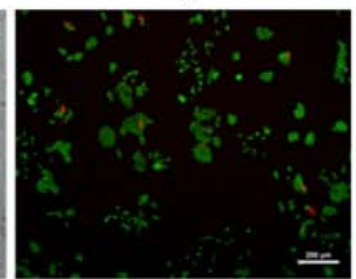

Figure 3. Representative micrographs of an air-interface culture (AIC) condition 3D spheroid formation including bright field images and final day fluorescent images (with respect to time) where green cells stained with calcein are alive and red cells stained with ethidium homodimer-1 are dead. Scale bar, $200 \mu \mathrm{m}$.

the end, these results demonstrate that paclitaxel retains its efficacy and activity against lung cancer cells after spray drying and increases the efficacy by its targeted delivery to the cells.

A 3D lung cancer multicellular spheroid (MCS) model was formed by seeding either A549 or H358 cells onto collagen in either liquid-covered culture (LCC) or air-interface culture (AIC) conditions. Fig. 3 shows micrographs of the resulting 3D spheroids grown in AIC conditions with time. For H358 cells, spheroids formed fairly quickly after seeding (within two days) with a distribution of sizes whereas A549 form loose spheroid aggregates only after 9 days of cell culture.
Spheroids grown in LCC conditions were visually the same in size and morphology as those in AIC conditions for both cell lines (data not shown). The spheroids were fluorescently stained to show cell viability and death after 6 or 12 days of culturing (H358 and A549 cells, respectively), which is the final growth time after treatment with PTX or PTX-loaded MPs. H358 cells were almost entirely alive (green) whereas A549 cells showed some cell death (red). These results indicate that the spheroids were able to maintain their growth profiles and stay alive with nutrient transfer through the collagen layer throughout their growth and treatment with paclitaxel. While efficacy experiments were completed on both cell lines, it may 

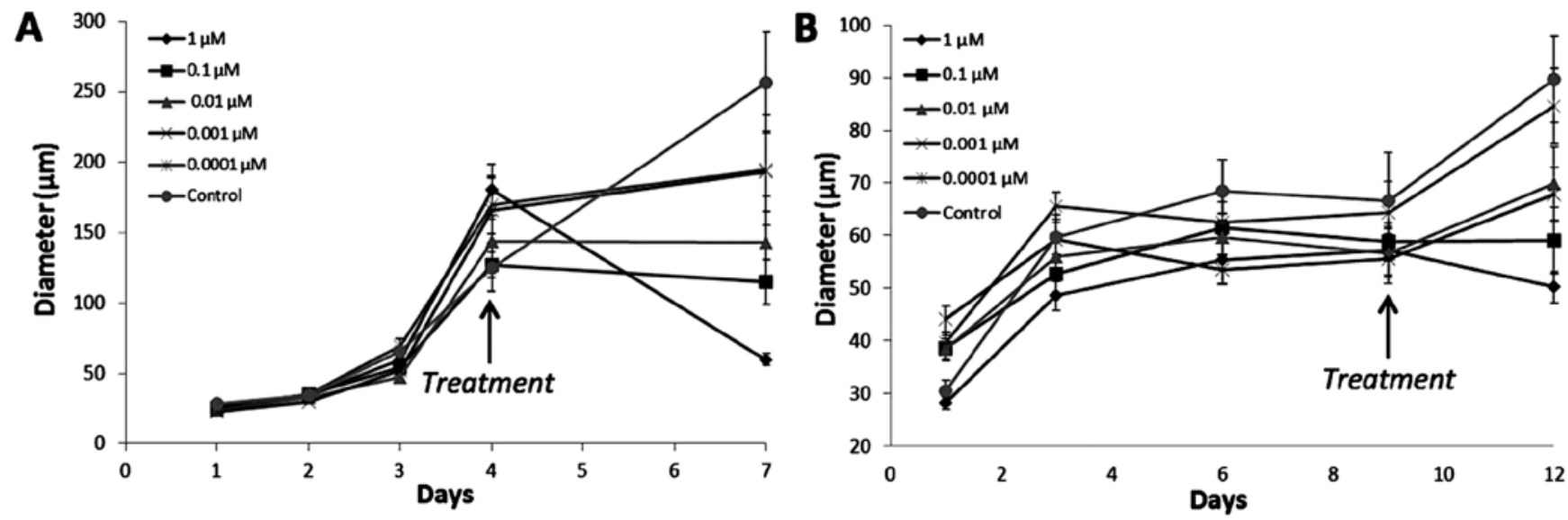

Figure 4. Spheroid diameter/growth curves for (A) H358 and (B) A549 3D spheroids in LCC conditions during spheroid formation and after treatment with paclitaxel in media.
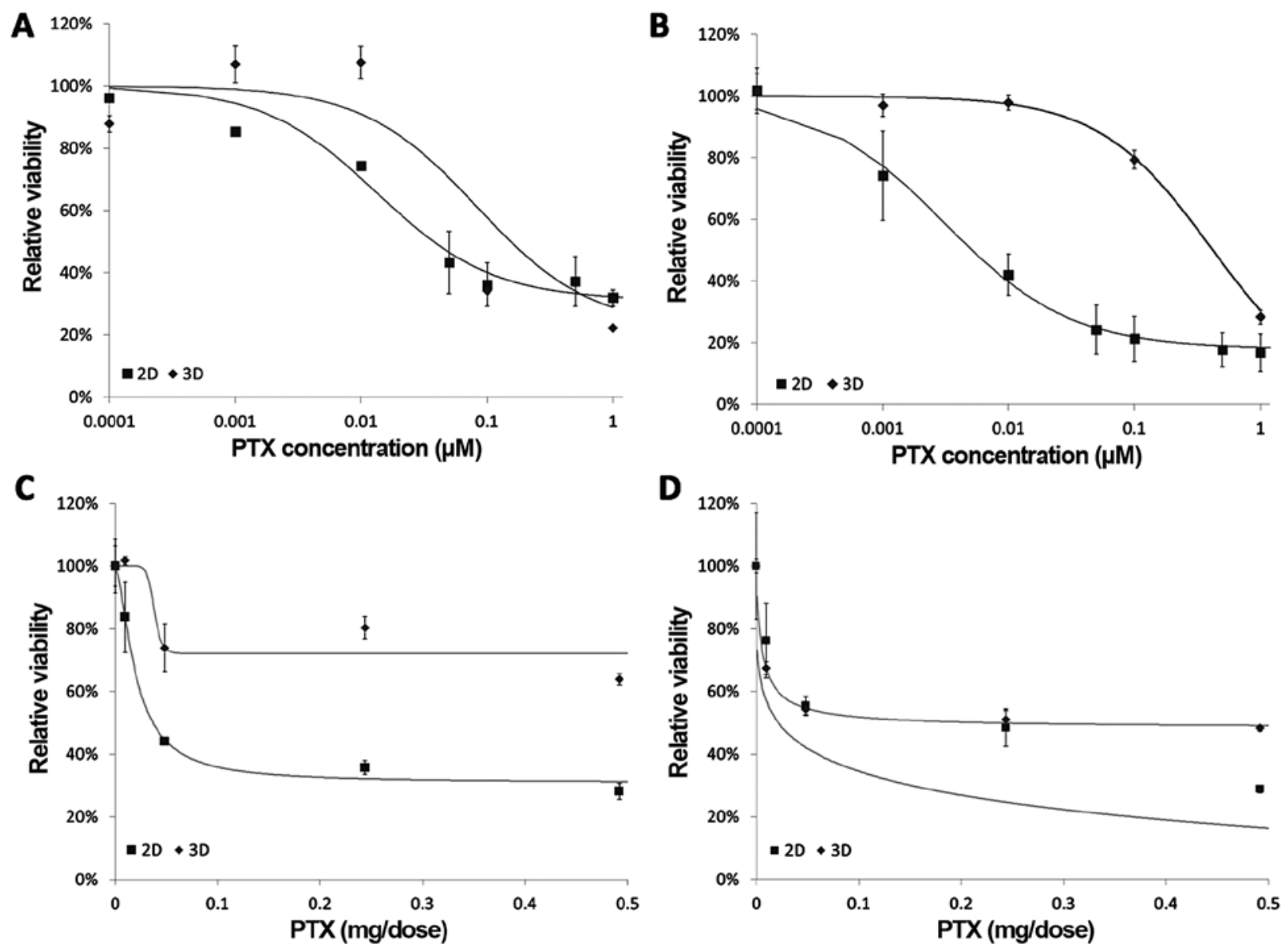

Figure 5. Dose-response curves of lung cancer cell lines exposed to PTX and PTX-loaded aerosol microparticles in the following conditions: (A) A549 cells exposed to raw PTX in LCC conditions, (B) H358 cells exposed to raw PTX in LCC conditions, (C) A549 cells exposed to PTX-loaded microparticles in AIC conditions, and (D) H358 cells exposed to PTX-loaded microparticles in AIC conditions.

be that $\mathrm{H} 358$ cells provide a better model for fully formed, spherical spheroids grown on collagen in the evaluation of lung anticancer therapeutics (Fig. 4).

To provide a baseline comparison to the 3D MCS models (both AIC and LCC), PTX and PTX-loaded particles were also evaluated using 2D-cultured cells in both LCC and AIC conditions, respectively. Dose-response curves for both cell types and both 2D and 3D culturing conditions can be seen in Fig. 5. The actual PTX dose for the AIC studies was determined by using the actual amount of PTX loaded in the particles (Table I) and the amount of powder dose provided to each sample/well of cells $(1 \mathrm{mg})$ resulting in units of $\mathrm{mg} / \mathrm{dose}$. The resulting $\mathrm{IC}_{50}$ values can be found in Table II. For LCC conditions, 3D cells exhibited a delayed lag in response on 

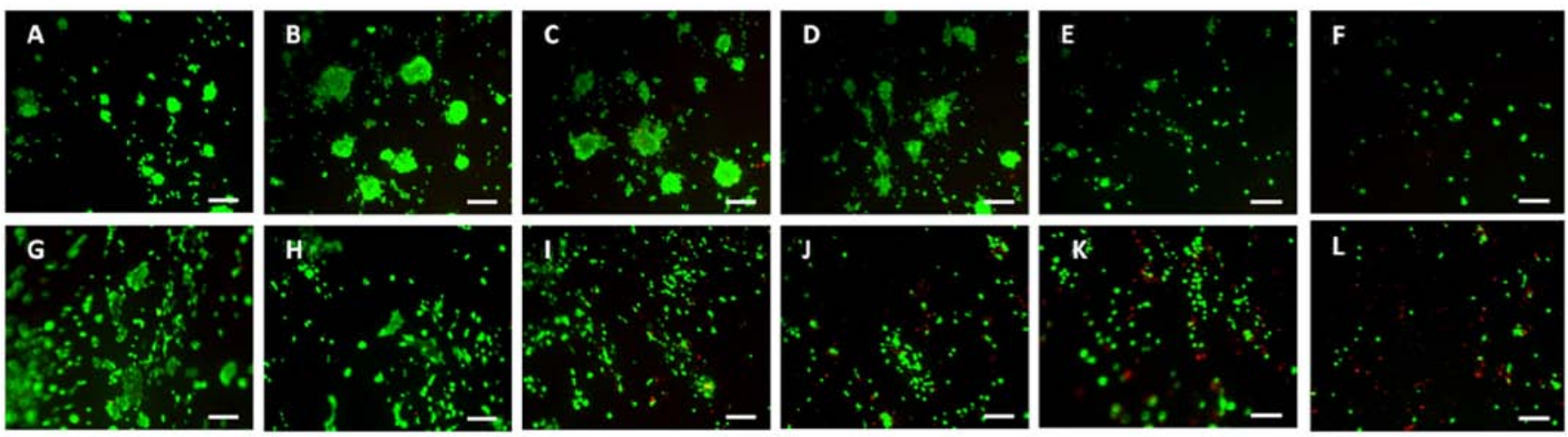

Figure 6. Fluorescent micrographs of spheroids grown in LCC conditions on the final day of raw PTX treatment. (A-F) are H358 cells exposed to 0, 0.0001 , $0.001,0.01,0.1$ and $1 \mu \mathrm{M}$ in corresponding order. (G-L) are A549 cells exposed to 0, 0.0001, 0.001, 0.01, 0.1 and $1 \mu \mathrm{M}$ in corresponding order. Scale bar, $200 \mu \mathrm{m}$.
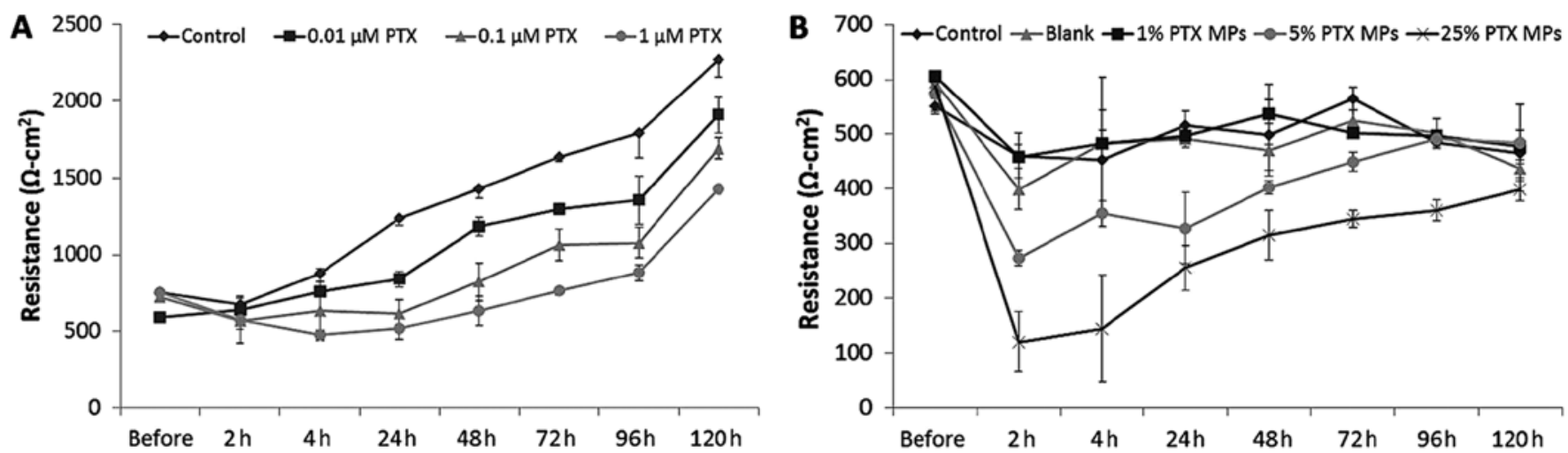

Figure 7. Transepithelial electric resistance (TEER) evaluation of Calu-3 monolayers grown in LCC (A) and AIC (B) conditions after exposure to paclitaxel and paclitaxel-loaded microparticles, respectively. Approximately $1 \mathrm{mg} / \mathrm{well}$ of liposphere particles were applied to each AIC sample.

the dose-response curve corresponding to higher $\mathrm{IC}_{50}$ values for both cell types in comparison to $2 \mathrm{D}$ cells $(0.0783$ and $0.0103 \mu \mathrm{M}$ PTX for H358 cells, 0.4065 and $0.0878 \mu \mathrm{M}$ PTX for A549 cells for 3D and 2D, respectively). These results indicate that spheroids are more resistant to PTX treatment in media, likely due to transport limitations into the spheroids providing a natural protection to the cells. For AIC conditions, A549 3D spheroids were more resistant to PTX-loaded PEGylated phospholipid MPs in comparison to 2D cells (991.02 versus $37.78 \mu$ g PTX, respectively). Similarly, H358 3D spheroid were also more resistant to PTX-loaded MPs in comparison to $2 \mathrm{D}$ where the $\mathrm{IC}_{50}$ values for AIC conditions were 5.29 and $20.03 \mu \mathrm{g}$ for $2 \mathrm{D}$ and $3 \mathrm{D}$, respectively. These results demonstrate the potential importance of evaluating lung anticancer therapeutics in $3 \mathrm{D}$ cell culture, as there is a significant difference in cellular responses between 2D and 3D systems. Furthermore, the culturing of lung cancer cells in AIC conditions as the resulting cellular responses may provide a more physiologically relevant model for anticancer therapeutic evaluation when validated against in vivo models and/or human clinical trials. In particular, the results reported for AIC evaluation were in $\mu \mathrm{g} /$ dose, thereby allowing for a simple determination of the dose that should be given to a patient in terms of $\mathrm{mg} / \mathrm{kg}$ via direct inhalation to the lung.

The size of the spheroids was evaluated over time both before and after treatment in LCC conditions to determine the effect of PTX exposure on the spheroid morphology as
Table II. $\mathrm{IC}_{50}$ values for A549 and $\mathrm{H} 358$ 2D cells and 3D spheroids in both LCC and AIC conditions.

\begin{tabular}{lccc}
\hline Cells & $\begin{array}{c}\text { Culture } \\
\text { condition }\end{array}$ & $\begin{array}{c}\text { LCC } \\
\text { PTX IC }_{50} \\
(\mu \mathrm{M})\end{array}$ & $\begin{array}{r}\text { AIC } \\
\text { PTX IC }_{50} \\
(\mu \mathrm{g} / \mathrm{dose})\end{array}$ \\
\hline H358 & 2D & 0.013 & 20.0 \\
& 3D & 0.084 & 39.2 \\
A549 & 2D & 0.084 & 5.3 \\
& 3D & 0.334 & 991.0 \\
\hline
\end{tabular}

seen in Fig. 6. For H358 cells, the spheroid sizes increased with time and were approximately $150 \mu \mathrm{m}$ in size after 4 days, which is when they were treated with PTX. At $72 \mathrm{~h}$ after PTX exposure, the spheroid size decreased significantly for cells exposed to $0.01,0.1$ and $1 \mu \mathrm{M}$ of PTX whereas those exposed to 0.0001 and $0.001 \mu \mathrm{M}$ PTX did not differ significantly from the control $(\mathrm{p}<0.05)$. Thus, there is a threshold value at which spheroid dissociation may occur when treating with PTX. A549 spheroids increased in size with time, reaching approximately $60 \mu \mathrm{m}$ in diameter after 9 days, which is when they were treated with PTX. At $72 \mathrm{~h}$ after treatment, the spheroid sizes decreased for cells exposed to $0.01,0.1$ and $1 \mu \mathrm{M}$ as with 
the $\mathrm{H} 358$ cells and remained the same size when exposed to 0.0001 and $0.001 \mu \mathrm{M}$ of PTX.

Transepithelial resistance (TEER) was evaluated by exposing 2D Calu-3 cells in AIC conditions to PEGylated phospholipid MPs containing PTX and LCC conditions to PTX in media. Fig. 7 shows the measured resistance of the Calu-3 cells after the described treatments up to five days where the initial treatment was done after the cells reached resistance equilibrium, which are similar to those previously reported in literature (31). For LCC cells, the resistance continued to increase for all systems up to five days, however, for cells exposed to 0.01 and $1 \mu \mathrm{M}$ PTX the resistance was initially stagnant before recovering and increasing with time. For AIC cells exposed to MPs, the resistance initially decreased for all cells (including the control) which is likely due to the addition of media, which could dilute any mucin present on the cell layers, thereby decreasing the resistance. Cells exposed to $25 \%$ PTX exhibited the most significant decrease in resistance along with those exposed to 5\% PTX, however, all samples recovered to the control resistance after 5 days (no significant difference, $\mathrm{p}<0.05$ ). These results demonstrate that while dry powder PEGylated phospholipid MPs used for aerosol delivery may initially have a detrimental effect on lung tissue, that it will subsequently recover and likely only result in temporary morbidity.

Overall, the given results demonstrate the validity of using an AIC 3D spheroid model in the evaluation of lung anticancer therapeutics, which is the first time this has been done. PEGylated phospholipid microparticles loaded with paclitaxel were evaluated by cells grown in AIC conditions, whereas PTX in media was evaluated by cells in 3D conditions. The actual PTX loading and resulting activity of the PTX in the particles was favorable (high loading and increased efficacy with particle delivery). Furthermore, the difference in cellular response in terms of $2 \mathrm{D}$ versus $3 \mathrm{D}$ and $\mathrm{AIC}$ versus $\mathrm{LCC}$ culturing conditions was demonstrated. Finally, the safety of the MPs was demonstrated by TEER evaluation. These methods provide the means to more thoroughly characterize dry powder aerosol particles (AIC conditions) and solutionbased aerosol particles (LCC conditions) for lung cancer aerosol therapeutics.

\section{Acknowledgements}

The authors gratefully acknowledge financial support from the National Cancer Institute (NCI) grant no. R25CA153954 and a National Cancer Institute Cancer Nanotechnology Training Center (NCI-CNTC) Postdoctoral Traineeship awarded to S.A.M. The content is solely the responsibility of the authors and does not necessarily represent the official views of the National Cancer Institute or the National Institutes of Health.

\section{References}

1. Society AC: Cancer Facts \& Figures 2013. American Cancer Society, Atlanta, GA, pp4-8, 2013.

2. Wisnivesky JP, Bonomi M, Henschke C, Iannuzzi M and McGinn T: Radiation therapy for the treatment of unresected stage I-II non-small cell lung cancer. Chest 128: 1461-1467, 2005 .
3. Pfister DG, Johnson DH, Azzoli CG, Sause W, Smith TJ, Baker S Jr, Olak J, Stover D, Strawn JR, Turrisi AT, et al; American Society of Clinical Oncology: American Society of Clinical Oncology treatment of unresectable non-small-cell lung cancer guideline: Update 2003. J Clin Oncol 22: 330-353, 2004.

4. Burdett E, Kasper FK, Mikos AG and Ludwig JA: Engineering tumors: A tissue engineering perspective in cancer biology. Tissue Eng Part B Rev 16: 351-359, 2010.

5. Nirmalanandhan VS, Duren A, Hendricks $P$, Vielhauer G and Sittampalam GS: Activity of anticancer agents in a threedimensional cell culture model. Assay Drug Dev Technol 8: 581-590, 2010.

6. Ivascu A and Kubbies M: Rapid generation of single-tumor spheroids for high-throughput cell function and toxicity analysis. J Biomol Screen 11: 922-932, 2006.

7. Lin R-Z and Chang HY: Recent advances in three-dimensional multicellular spheroid culture for biomedical research. Biotechnol J 3: 1172-1184, 2008.

8. Ingram M, Techy GB, Ward BR, Imam SA, Atkinson R, Ho H and Taylor CR: Tissue engineered tumor models. Biotech Histochem 85: 213-229, 2010.

9. Goodman TT, Chen J, Matveev K and Pun SH: Spatio-temporal modeling of nanoparticle delivery to multicellular tumor spheroids. Biotechnol Bioeng 101: 388-399, 2008.

10. Goodman TT, Olive PL and Pun SH: Increased nanoparticle penetration in collagenase-treated multicellular spheroids. Int J Nanomed 2: 265-274, 2007.

11. Smalley KSM, Lioni M and Herlyn M: Life isn't flat: Taking cancer biology to the next dimension. In Vitro Cell Dev Biol Anim 42: 242-247, 2006.

12. Friedrich J, Ebner R and Kunz-Schughart LA: Experimental anti-tumor therapy in 3-D: Spheroids - old hat or new challenge? Int J Radiat Biol 83: 849-871, 2007.

13. Tazzyman S, Barry ST, Ashton S, Wood P, Blakey D, Lewis CE and Murdoch C: Inhibition of neutrophil infiltration into A549 lung tumors in vitro and in vivo using a CXCR2-specific antagonist is associated with reduced tumor growth. Int J Cancer 129: 847-858, 2011.

14. Fjellbirkeland L, Bjerkvig R and Laerum OD: Tumour fragment spheroids from human non-small-cell lung cancer maintained in organ culture. Virchows Arch 426: 169-178, 1995.

15. Vertrees RA, McCarthy M, Solley T, Popov VL, Roaten J, Pauley M, Wen X and Goodwin TJ: Development of a threedimensional model of lung cancer using cultured transformed lung cells. Cancer Biol Ther 8: 356-365, 2009.

16. Jin H-J, Cho Y-H, Gu J-M, Kim J and Oh Y-S: A multicellular spheroid formation and extraction chip using removable cell trapping barriers. Lab Chip 11: 115-119, 2011.

17. Hendricks P, Diaz FJ, Schmitt S, Sittampalam GS and Nirmalanandhan VS: Effects of respiratory mechanical forces on the pharmacological response of lung cancer cells to chemotherapeutic agents. Fundam Clin Pharmacol 26: 632-643, 2012.

18. Hehlgans S, Lange I, Eke I and Cordes N: 3D cell cultures of human head and neck squamous cell carcinoma cells are radiosensitized by the focal adhesion kinase inhibitor TAE226. Radiother Oncol 92: 371-378, 2009.

19. Grainger CI, Greenwell LL, Lockley DJ, Martin GP and Forbes B: Culture of Calu-3 cells at the air interface provides a representative model of the airway epithelial barrier. Pharm Res 23: 1482-1490, 2006.

20. Forbes B, Hashmi N, Martin GP and Lansley AB: Formulation of inhaled medicines: Effect of delivery vehicle on immortalized epithelial cells. J Aerosol Med 13: 281-288, 2000.

21. Forbes B and Ehrhardt C: Human respiratory epithelial cell culture for drug delivery applications. Eur J Pharm Biopharm 60: 193-205, 2005.

22. Grainger CI, Greenwell LL, Martin GP and Forbes B: The permeability of large molecular weight solutes following particle delivery to air-interfaced cells that model the respiratory mucosa. Eur J Pharm Biopharm 71: 318-324, 2009.

23. Haghi M, Young PM, Traini D, Jaiswal R, Gong J and Bebawy M: Time- and passage-dependent characteristics of a Calu-3 respiratory epithelial cell model. Drug Dev Ind Pharm 36: 1207-1214, 2010.

24. Schiller JH, Harrington D, Belani CP, Langer C, Sandler A, Krook J, Zhu J and Johnson DH; Eastern Cooperative Oncology Group: Comparison of four chemotherapy regimens for advanced non-small-cell lung cancer. N Engl J Med 346: 92-98, 2002. 
25. Kelly K, Crowley J, Bunn PA Jr, Presant CA, Grevstad PK, Moinpour CM, Ramsey SD, Wozniak AJ, Weiss GR, Moore DF, et al: Randomized phase III trial of paclitaxel plus carboplatin versus vinorelbine plus cisplatin in the treatment of patients with advanced non-small-cell lung cancer: A Southwest Oncology Group trial. J Clin Oncol 19: 3210-3218, 2001.

26. Alipour S, Montaseri $\mathrm{H}$ and Tafaghodi M: Preparation and characterization of biodegradable paclitaxel loaded alginate microparticles for pulmonary delivery. Colloids Surf B Biointerfaces 81: 521-529, 2010.

27. Koshkina NV, Golunski E, Roberts LE, Gilbert BE and Knight V: Cyclosporin A aerosol improves the anticancer effect of paclitaxel aerosol in mice. J Aerosol Med 17: 7-14, 2004

28. Koshkina NV, Waldrep JC, Roberts LE, Golunski E, Melton S and Knight V: Paclitaxel liposome aerosol treatment induces inhibition of pulmonary metastases in murine renal carcinoma model. Clin Cancer Res 7: 3258-3262, 2001.
29. Meenach SA, Vogt FG, Anderson KW, Hilt JZ, McGarry RC and Mansour HM: Design, physicochemical characterization, and optimization of organic solution advanced spray-dried inhalable dipalmitoylphosphatidylcholine (DPPC) and dipalmitoylphosphatidylethanolamine poly(ethylene glycol) (DPPE-PEG) microparticles and nanoparticles for targeted respiratory nanomedicine delivery as dry powder inhalation aerosols. Int $\mathbf{J}$ Nanomed 8: 275-293, 2013.

30. Meenach SA, Anderson KW, Zach Hilt J, McGarry RC and Mansour HM: Characterization and aerosol dispersion performance of advanced spray-dried chemotherapeutic PEGylated phospholipid particles for dry powder inhalation delivery in lung cancer. Eur J Pharm Sci 49: 699-711, 2013.

31. Foster KA, Avery ML, Yazdanian M and Audus KL: Characterization of the Calu-3 cell line as a tool to screen pulmonary drug delivery. Int J Pharm 208: 1-11, 2000. 